\title{
An automated technique for the study of cyclic fluctuations in sexual motivation in an avian species
}

\author{
HAKAN ÇETINKAYA and MICHAEL DOMJAN \\ University of Texas, Austin, Texas
}

\begin{abstract}
Diurnal fluctuations in sexual behavior occur in freely interacting pairs of male and female birds. These fluctuations are difficult to interpret because they may reflect fluctuations in the motivation of the male, the motivation of the female, or both. A method was developed to study the sexual motivation of male Japanese quail in response to a standard stimulus. Sexual behavior was elicited by a taxidermic model of a female quail in a squatting posture. Sensors beneath and in the back of the model served to detect when the male mounted and made cloacal contact with the model. The technique allowed continuous recording of male sexual behavior under standard conditions. When males were maintained on a photoperiod with lights on at $0600 \mathrm{~h}$ and off at $2200 \mathrm{~h}$, sexual behavior peaked in the early afternoon, with a secondary peak just before lights-out.
\end{abstract}

Studies of chronobiology have revealed cyclic fluctuations in a variety of aspects of physiology and behavior including phototaxis in algae (Euglena gracilis), oxygen uptake in Microtus arvalis, fur renewal in Lynx canadensis, nest building in rats, and locomotor activity in the fiddler crab (Uca pugnax) (Saunders, 1977). The periodicity of some biorhythms is on the order of seconds or milliseconds (e.g., pacemaker activity in the parietal ganglion of Helix pomatia, Aschoff, 1981). Other systems fluctuate over hours, days, or months (e.g., circadian fluctuations in crowing in male Japanese quail, Coturnix coturnix japonica, Guyomarc'h \& Guyomarc'h, 1994; circalunar changes in locomotor activity in Typosyllis, Franke, 1985; circannual changes in gonadal function in the European starling, Sturnis vulgaris, Eberhard, 1975). Physiological and behavioral parameters may also show both short-term and long-term fluctuations. For example, crowing is evident in Japanese quail only during the breeding season but occurs with a circadian periodicity at that time.

The study of short-term rhythmic fluctuations requires frequent measurement of the parameter of interest. In contrast, long-term fluctuations may be detected with more widely spaced data sampling. In either case, as Enright (1981) noted, "a detailed analysis of a given rhythmic system has rarely (if ever) been accomplished without the development of some sort of automatic or at least semi-automatic data-collecting technique" (p. 12).

The present study focused on developing an automated technique for the study of periodicities in the cop-

The research was supported by Grant MH39940 from the National Institute of Mental Health. The authors thank Ed Pasanen for his advice and encouragement. Correspondence should be addressed to M. Domjan, Department of Psychology, University of Texas, Austin, TX 78712 (e-mail: domjan@psy.utexas.edu). ulatory behavior of male quail. Fluctuations in quail sexual behavior have been previously investigated using an observational sampling procedure (Ottinger, Schleidt, \& Russek, 1982). An experimenter observed the copulatory attempts of males for different $2-3$-h periods on different days, until all daylight hours had been sampled twice. This procedure revealed peaks in copulatory behavior in the late morning and early evening. However, the observational procedure did not provide continuous data on the behavior of individual subjects. In addition, because live females served as copulation partners, one could not determine whether changes in the copulatory behavior of the males reflected changes in male sexual motivation or fluctuations in female receptivity (Delville, Sulon, \& Balthazart, 1986).

Automated techniques for the measurement of sexual behavior have been developed previously for small mammals. Peirce and Nuttall (1961) detected copulation in rats by attaching electrodes to the male and the female and measuring the resistance between them. Moist softtissue contact involved in intromission was evidenced by substantial decreases in electrical resistance. In a related technique developed for rabbits, Rubin and Azrin (1967) also attached electrodes to the male and the female and detected intromission by an increase in current flow when intromission occurred. In another technique developed for rabbits (Contreras \& Beyer, 1979), an accelerometer was attached to the pelvis of the male to detect pelvic thrusting. These techniques have provided objective and detailed measurements of mammalian copulatory behavior and have revealed both short- and longterm fluctuations (Rubin \& Azrin, 1967). However, because they involved measuring interactions between live males and females, it was not possible to isolate fluctuations in male sexual behavior from changes in female receptivity. 
In the present study, a method was developed that permits the automatic and continuous recording of male copulatory behavior in an avian species. We were particularly interested in developing a technique that would measure behavior in response to a standard female stimulus so that changes in male behavior could not be attributed to changes in female receptivity.

Male domesticated quail (Coturnix japonica) served as subjects. Copulation in male quail begins with the male grabbing the back of the female's head or neck. The male then mounts by placing both feet on the back of the female. The mount response is followed by the male arching its back (with wings extended for balance) and thrusting its cloaca in contact with the cloaca of the female.

A live sexually receptive female is usually required to elicit male copulatory behavior in sexually inexperienced quail. However, sexually experienced males will also grab, mount, and make cloacal contact with a taxidermic model of a female (Crawford \& Akins, 1993; Crawford, Akins, \& Domjan, 1994). We took advantage of this finding and tested male quail with a taxidermic model of a female that was outfitted with sensors to automatically record mount and cloacal contact responses.

\section{METHOD}

\section{Subjects}

Four male Japanese quail (Coturnix japonica) were obtained from the quail colony maintained at the University of Texas at Austin. The birds were 7 months old and ranged in weight from 155 to $167 \mathrm{~g}$. They previously served in a sexual conditioning experiment that provided them with 15 opportunities to copulate with a sexually active female. Thus, they had extensive prior sexual experience. In addition, only subjects that readily copulated with a female in the experimental chambers before the start of the present study were tested with the taxidermic models.

\section{Experimental Chambers}

Four experimental chambers were used, one for each male. The chambers were $67.31 \mathrm{~cm}$ high, $121.92 \mathrm{~cm}$ deep, and $121.92 \mathrm{~cm}$ wide. The top, front, back, and one side wall were made of plywood and painted white. The floor and the other side wall were made of wire mesh. The wire-mesh wall was hinged so that it could be used as a service door. The wire-mesh wall also permitted visual access to the experimental chamber.

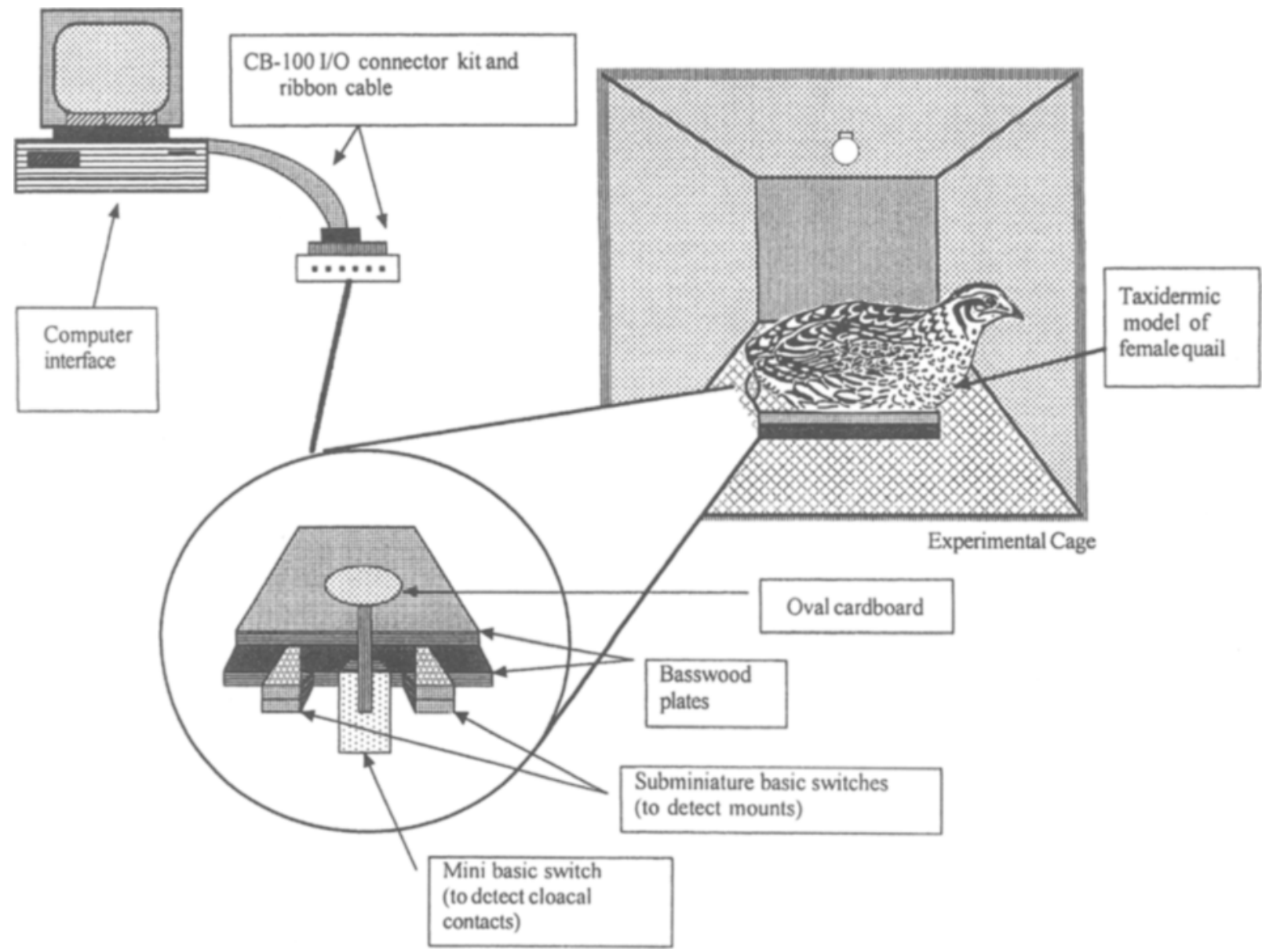

Figure 1. Schematic diagram of the taxidermic model used in the experiment, showing the sensors and computer interface. 


\section{Taxidermic Model and Response Detectors}

A taxidermic model of an adult reproductively active female quail was placed in the center of each experimental chamber. In preparation for taxidermy, a female with good plumage was sacrificed with $\mathrm{CO}_{2}$ and cooled in a refrigerator overnight. All body parts except the skull and wing and leg bones were removed through an abdominal incision. The skin was then cleaned with Borax and stretched over an artificial body made of cloth and filled with soft plastic fiber (Polyfil). The artificial body was made so that the model would be in a squatting position, similar to the posture of a sexually receptive female (Noble, 1973).

The taxidermic model was secured to a small wooden platform and provided with switches to detect copulatory behavior (see Figure 1). To detect mount responses, two Subminiature Basic Switches (SBS) with a standard flat lever (Selecta Switch, Inc., Model UM50E70C01-BG) were placed beneath the back of the model (see Figure 1). These switches had silver contacts and required a force of $58 \mathrm{~g}$ for operation. Because the average weight of the models was $43.8 \mathrm{~g}$ (range $40-50 \mathrm{~g}$ ), the switches were in the open position until a male mounted. The two switches were connected in parallel so that activation of either switch was recorded as a mount response.

To detect cloacal contact responses, a Mini Basic Switch (MBS) with a long lever (Selecta Switch, Inc., Model V3L-2106-D8-BG) was used. This switch required a force of $16.2 \mathrm{~g}$ to operate. An oval piece of cardboard (axes 30 and $35 \mathrm{~mm}$ ) was glued to the upper $15 \mathrm{~mm}$ of the lever to serve as an artificial cloaca (see Figure 1).

\section{Computer Interface}

A National Instruments interface board (NB-DIO-96) was connected to the NuBus port of a Macintosh 7200 PPC computer. This interface board has four 82C55A PPI chips that control 96 parallel digital input/output ( $\mathrm{L} / \mathrm{O})$ channels. Because only micro type switches were used, the internal power supply $(+5 \mathrm{~V})$ of the computer could be used to create digital signals through the switches. The signals were transferred from the switches to the data acquisition interface board via a CB-100 I/O connector kit (No. 776455-02, National Instruments) and a ribbon cable (NB5, National Instruments).

\section{Software}

A graphical programming language (LabVIEW, National Instruments) was used for experimental control and data collection (Wells \& Travis, 1997). LabVIEW enables the creation of programs in pictorial form. This eliminates the syntactic details of traditional programming languages. LabVIEW programs are constructed from a rich library of virtual instruments or programming modules that can operate in parallel.

The front panel of the LabVIEW program created for the study had three major sections (see Figure 2). The first served to identify the experimental session and permitted adjustment of the sampling rate for each response to be measured. "Device Number" showed the number of the NuBus slot of the computer that was used for the data acquisition board. Below the slot number, the status of the experiment was indicated by the color of a light.

The middle section of the front panel indicated how the input channels were distributed among the 4 subjects and the two responses being monitored. The eighth port of the NB-DIO-96 data-acquisition board was used. This port has eight channels or lines. Two lines were used for each subject, one for the cloacal contact response and the other for the mount response. A light below each response changed from blue to red whenever that response was detected.

The second panel of the program was a block diagram of the data acquisition functions (see Figure 3). A case structure was used first

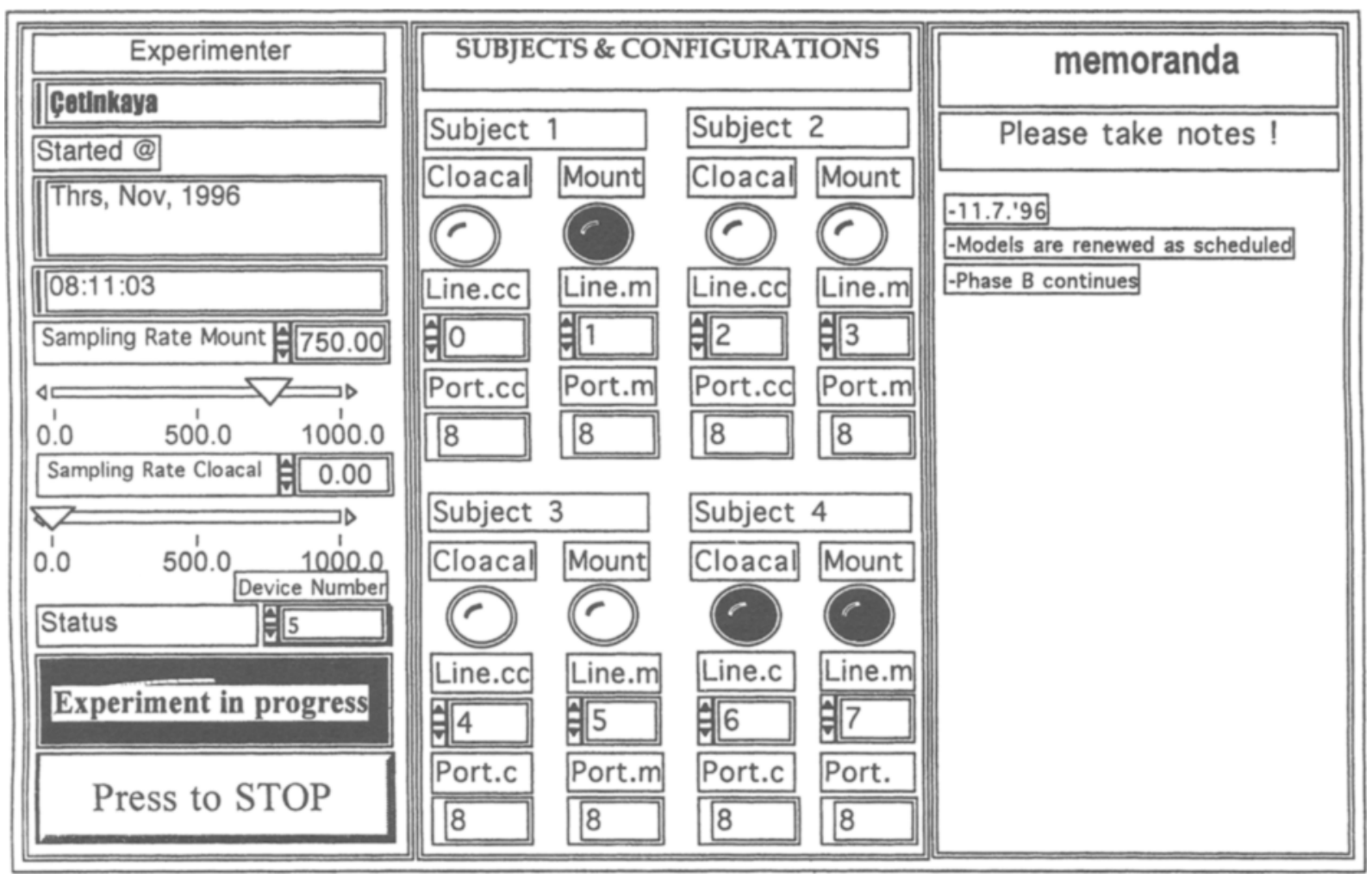

Figure 2. The front panel of the LabVIEW program. 


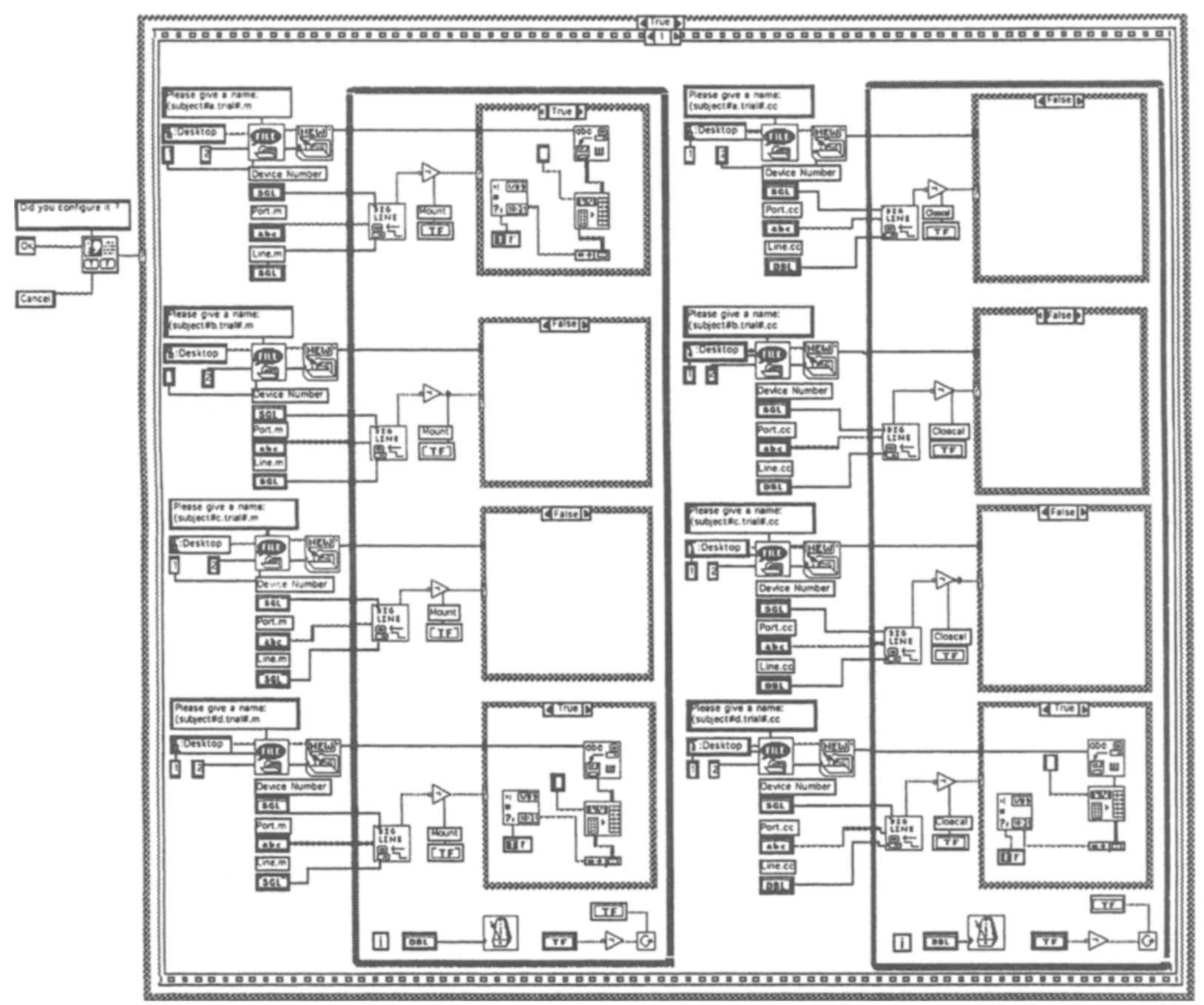

Figure 3. Block diagram of the data acquisition functions of the LabVIEW program.

to decide whether or not the experiment could be started. This decision was based on whether or not the front panel parameters had been set. Other case structures were then used with the detectors for each response to decide whether or not a response occurred. A mount response was registered when the mount detectors were activated for at least $1.0 \mathrm{sec}$. A cloacal contact response was registered when its detector was activated for at least $0.2 \mathrm{sec}$. Whenever the input decision was "yes" or "true," the operation inside the case frame was executed.

The software also employed the "sequence" structure, which executes its subdiagrams in numeric order. Two program components were executed in sequence. When the experimenter completed the program configuration, as specified in panel 1 (see Figure 2 ), the 0 order sequence was executed, which involved registering demographic information (date, time, and name of experimenter). This was followed by the first order sequence, which involved operations such as creating/opening a filing and recording data in a file. The first order sequence also included a "while loop," which repeats a section of code until a condition is met. The while-loop frame specified the data sampling rate and recorded the inputs from the response detectors in a spreadsheet file. The while loop continued to execute until the experiment was terminated.
Because we were interested in time-dependent fluctuations in sexual behavior, the data acquired were time stamped in the format HH:MM:SS. A new response was recorded when there was a break of at least $1.0 \mathrm{sec}$ from the previous response. For each subject, data files were created for mount and cloacal contact responses. Each file was named according to the type of response, subject number, and date. Because the time stamps were in spreadsheet format, the files could be analyzed using Excel Visual Basic Version $5.0(\mathrm{Mi}$ crosoft Corp. 1993-1994).

\section{Procedure}

The birds were moved to the experimental chambers 2 weeks prior to the start of the experiment, and they remained there throughout the experiment. Food and water were available continuously. During each of the last four days before the start of data collection, a female bird was placed with each male for $5 \mathrm{~min}$, and the 2 birds were permitted to copulate. This served to establish an association between the contextual cues of the experimental chamber and sexual reinforcement, and it was expected to facilitate copulation with the taxidermic models (Domjan, Greene, \& North, 1989). Only birds that copulated with the live females were tested with the taxidermic models. 
The experiment started when a taxidermic model of a female was placed in the center of the experimental chamber. As the subject repeatedly grabbed and mounted the model, the model gradually lost its feathers, especially in the head and neck areas. To compensate for this, each model was replaced with a new one every 3-4 days during the 15 days of the experiment. The introduction of a new model sometimes elevated the overall rate of responding, but it did not appear to influence the diurnal cyclicity of the sexual behavior.

\section{RESULTS}

All of the subjects repeatedly copulated with the taxidermic models during the course of the experiment. The sensors used to detect the mount and cloacal contact responses remained functional for the 15 days of the experiment and did not require replacement.

Entrainment to the 16:8-h light:dark photoperiod was evident in all 4 subjects. Little copulatory behavior occurred during nighttime hours $(2200$ to $0600 \mathrm{~h})$ when the lights in the laboratory were off. Copulatory behavior fluctuated in a systematic manner during daylight hours, and similar changes were evident on each day of the experiment.

Figure 4 shows the mean frequency of the mount response for the 4 subjects on Day 15 of the experiment. (Cloacal contact responses showed a similar circadian pattern.) The data were summed over different observation periods. Panel A shows the data accumulated in 30min blocks. In panel B, the data were summed in $1-h$ blocks. Panels C and D show the same data in 2-h and 4-h blocks, respectively. Regardless of how the data were blocked, a major peak in sexual activity was evident in the early afternoon hours, followed by a decline that lasted until 1800 to $2000 \mathrm{~h}$. A secondary peak was also evident shortly before the lights were turned off.

Similar results were obtained with the 4 subjects. The modest degree of variability (shown by the standard error bars in Figure 4) permitted strong discrimination between the high and low points of activity. More frequent local peaks in responding were evident when the data were summed over 30-min or 1-h periods (panels A

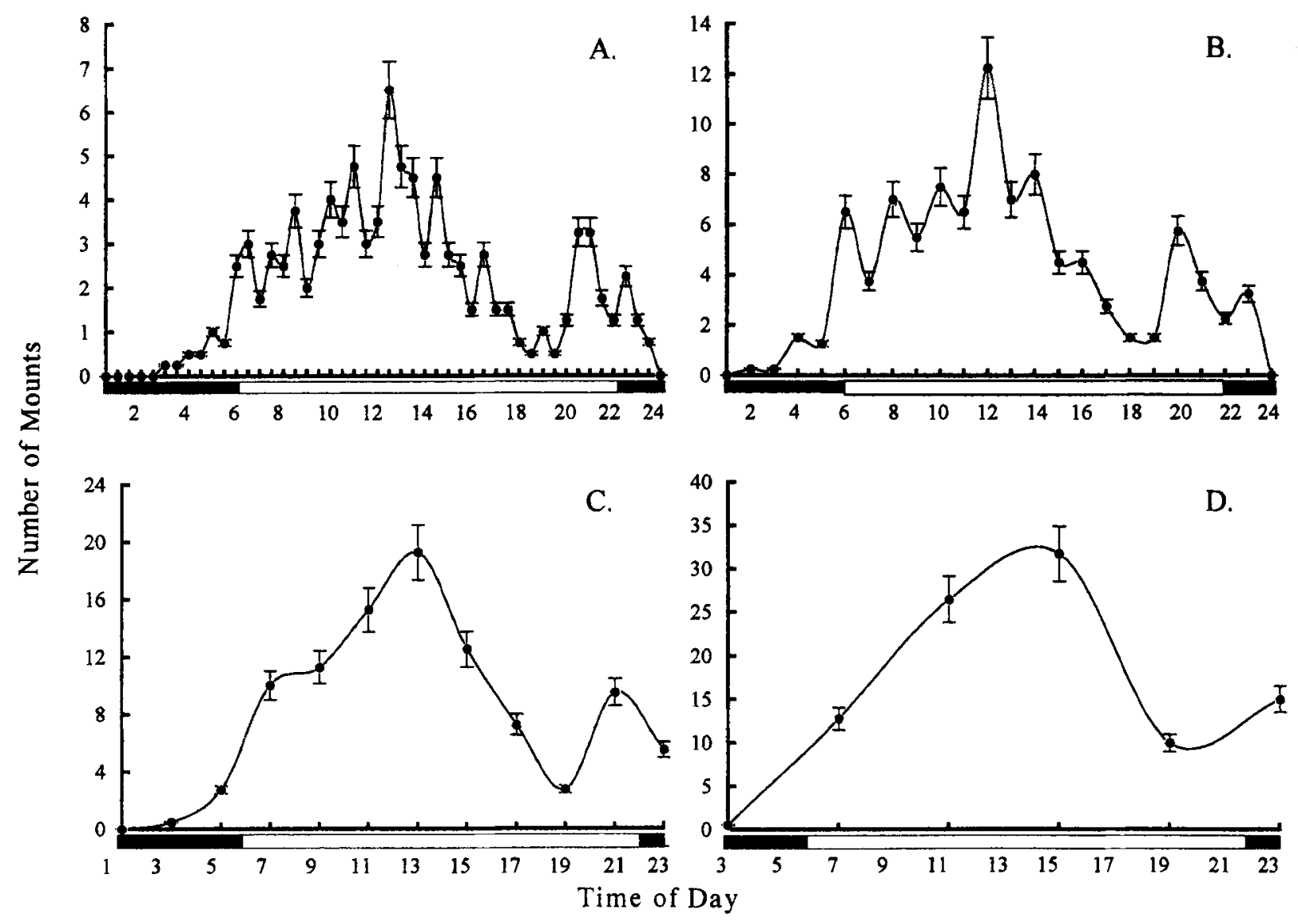

Figure 4. Mean ( $\pm S E$ ) number of mount responses of the 4 subjects summed over $0.5-, 1-, 2-$, and 4-h blocks (panels $A, B, C$, and $D$, respectively). Periods of darkness are depicted by the shaded bars on the abscissa. (Note that the ordinate is different for each panel.) 

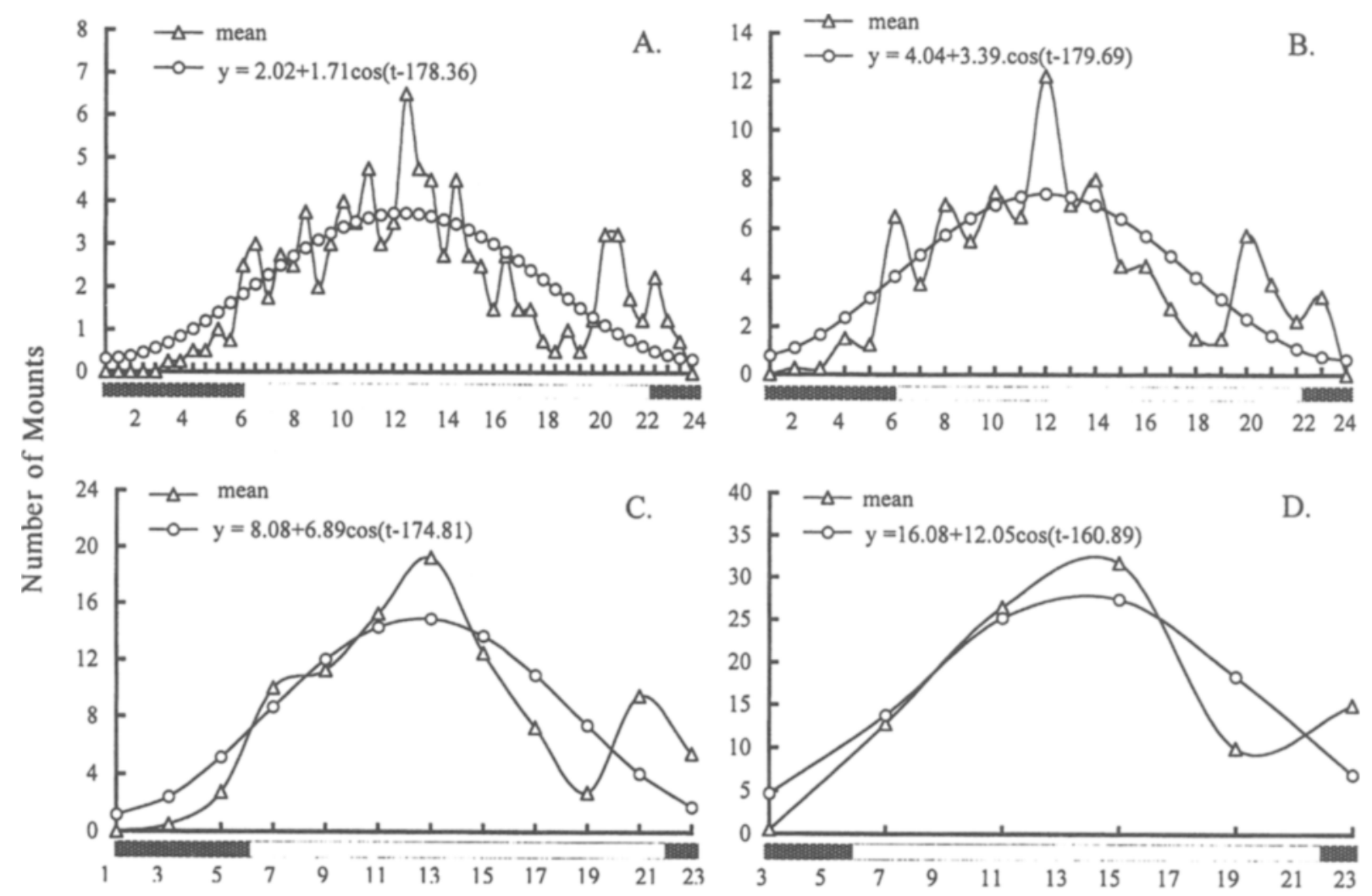

Time of Day

Figure 5. Mean obtained data (open triangles) and best-fitting cosine function (open circles) for the data summed over 0.5-, 1-, 2-, and 4-h blocks (panels $A, B, C$, and $D$, respectively).

and B) than when larger groupings of the data were used. Much of the fine grain of the cyclic pattern was lost when the data were summed over 2 -h or 4 -h periods (panels $\mathrm{C}$ and $\mathrm{D}$ ).

To evaluate the periodicity of the data, we employed a periodic regression model (Batschelet, 1981). The model generates a cosine function given by the equation:

$$
y=M+A \cos \omega(t-\phi),
$$

in which $t$ represents the independent variable time, $M=$ mean level or mesor, $A=$ amplitude, $\omega=$ angular frequency, and $\phi=$ acrophase or time of peak responding. The parameter $\omega=2 \pi / T$. In our case, $T$ was $24 \mathrm{~h}$ or $360^{\circ}$, which made the value of $\omega$ equal to 1.0 .

Using this model, we calculated the best-fitting cosine function for the data summed over 0.5-, 1-, 2-, and 4-h blocks and obtained estimates of the amplitude and the acrophase in each case. Figure 5 shows the functions obtained in this manner (as well as their equations) laid over the mean obtained values. Blocking the data over different intervals resulted in different estimates of the acrophase or time of peak responding. When the data were summed over $0.5-, 1-$, and 2-h blocks (panels A, B, and $C$, respectively), the acrophase values were fairly similar: 1211,1202 , and $1235 \mathrm{~h}$, respectively. The acrophase shifted to $1316 \mathrm{~h}$ when the data were summed over 4-h blocks (panel D). As expected, blocking the data over different intervals also affected the amplitude of the best-fitting cosine function. The amplitudes were $1.71,3.39,6.89$, and 12.05 for $0.5-, 1-, 2-$, and $4-h$ time blocks, respectively.

\section{DISCUSSION}

The technique developed in the present study permits continuous and objective measurement of the copulatory behavior of a male bird unconfounded by changes in female sexual receptivity. As far as we know, Rubin and Azrin (1967) conducted the only previous study in which copulatory behavior was recorded for long periods with an automated objective technique. Rubin and Azrin inferred the occurrence of intromission from an increase in current flow between male and female rabbits that were together for 3-61 days. The results obtained with the rabbits contrast with our findings in several important respects. The rabbits were sexually active mostly at night, whereas the quail showed a peak in their sexual activity during daylight hours. In addition, the rabbits showed 
periods of sexual inactivity that lasted as long as 16 and 20 days. Such long durations of sexual quiescence did not occur with the quail. The quail continued to show vigorous sexual activity each day. The extended periods of sexual inactivity observed in the rabbits may have been related to periods of female nonreceptivity. Female nonreceptivity could not contribute to the results obtained with the quail because the technique used with the quail involved a standard inanimate female stimulus.

The diurnal fluctuation in male sexual behavior that we observed with the automated procedure is consistent with what was reported by Ottinger et al. (1982). Using a time-sampling procedure carried out by a human observer, Ottinger et al. found two daily peaks in copulatory behavior, one around noon and the other in the evening. However, the measurement technique Ottinger et al. used did not permit discriminating between the vigor of the midday and the evening bursts of copulation. In the present study, copulation was more vigorous in the midday peak than in the evening peak.

Ottinger et al. (1982) suggested that the decline in copulatory behavior that occurs in the afternoon may be related to the egg-laying cycle and receptivity of the female. Changes in female receptivity cannot explain the afternoon decline that we observed because we used a standard inanimate female stimulus.

The fine-grain quantitative measurements provided by the present technique can be used to investigate the mechanisms responsible for the cyclic fluctuations in sexual behavior. The rhythmicities may be related to the photoperiod, to rhythmic fluctuations in the hormonal substrates of copulatory behavior, or to factors inherent in the behavior, such as fatigue or satiation. Future research is required to examine these possibilities.

\section{REFERENCES}

AsCHOFF, J. (1981). Annual rhythms in man. In J. Aschoff (Ed.), Handbook of behavioral neurobiology (Vol. 4, pp. 475-490). New York: Plenum.
Batschelet, E. (1981). Circular statistics in biology. New York: Academic Press.

Contreras, J. L., \& Beyer, C. (1979). A polygraphic analysis of mounting and ejaculation in the New Zealand white rabbit. Physiology \& Behavior, 23, 939-943.

CRAWford, L. L., \& AKINS, C. K. (1993). Stimulus control of copulatory behavior in male Japanese quail. Poultry Science, 72, 722-727.

Crawford, L. L., Akins, C. K., \& Domjan, M. (1994). Stimulus control of copulatory behavior in sexually naive male Japanese quail (Coturnix japonica): Effects of test context and stimulus movement. Journal of Comparative Psychology, 108, 252-261.

Delville, Y., Sulon, J., \& BalthazarT, J. (1986). Diurnal variations of sexual receptivity in the female Japanese quail (Coturnix coturnix japonica). Hormones \& Behavior, 20, 13-33.

Doman, M., Greene, P., \& North, C. (1989). Contextual conditioning and the control of copulatory behavior by species-specific sign stimuli in male Japanese quail, Journal of Experimental Psychology: Animal Behavior Processes, 15, 147-153.

EBERHARD, G. (1975). Effect of social stimuli on the circannual rhythm of gonadal function in the European starling (Sturnis vulgaris). Zeitschrift für Tierpsychologie, 38, 34-43.

ENRIGHT, J. T. (1981). Methodology. In J. Aschoff (Ed.), Handbook of behavioral neurobiology (Vol 4, pp. 11-19). New York: Plenum.

FRANKE, H.-D. (1985). On a clocklike mechanism timing lunar-rhythmic reproduction in Typosillis polifera (Polychaeta). Journal of Comparative Physiology, A156, 553-561.

Guyomarc'H, C., \& GuYomarC'H, J. C. (1994). Influence of a daily cycle of crowing on mature male Japanese quail. Comptes rendus de l'Academie des Sciences: Série III. Sciences de la vie, 317, 621-626.

NoBlE, R. (1973). Hormonal control of receptivity in female quail ( $\mathrm{Co}$ turnix coturnix japonica). Hormones \& Behavior, 4, 61-72.

OtTINGer, M. A., SCHLEIDT, W. M., \& RusseK, E. (1982). Daily patterns of courtship and mating behavior in the male Japanese quail. Behavioural Processes, 7, 223-233.

PeirCE, J. T., \& NuTTALL, R. L. (1961). Duration of sexual contacts in the rat. Journal of Comparative \& Physiological Psychology, 54, 585-587.

Rubin, H. B., \& AzRin, N. H. (1967). Temporal patterns of sexual behavior in rabbits as determined by an automatic recording technique. Journal of the Experimental Analysis of Behavior, 10, 219-231.

SAUNDERS, D. S. (1977). An introduction to biological rhythms. New York: Halstead.

WELls, L., \& TRAVIS, J. (1997), LabVIEW for everyone: Graphical programming made easier. Englewood Cliffs, NJ: Prentice-Hall.

(Manuscript received April 25, 1997;

revision accepted for publication July 21,1997 .) 